\title{
Analysis of dynamic tyrosine phosphoproteome in LFA-1 triggered migrating T-cells
}

NAVIN K. VERMA ${ }^{1 *}$, EUGENE DEMPSEY ${ }^{1}$, MICHAEL FREELEY ${ }^{1}$, CATHERINE H. BOTTING ${ }^{2}$, AIDEEN LONG ${ }^{1}$, DERMOT KELLEHER $^{1 \S}$, AND YURI VOLKOV $^{1 \S}$

${ }^{1}$ Department of Clinical Medicine, Institute of Molecular Medicine, Trinity College Dublin, Ireland

${ }^{2}$ BMS Mass Spectrometry and Proteomics Facility, Centre for Biomolecular Sciences, University of St Andrews, Scotland, UK

$\S$ These authors contributed equally to this manuscript.

Additional Supporting Information may be found in the online version of this article.

Received 7 July 2010; Revised 8 September 2010; Accepted 28 September 2010 Journal of Cellular Physiology (C) 2010 Wiley-Liss, Inc. DOI 10.1002/jep.22478 
${ }^{*}$ Correspondence to: Navin K. Verma, Cell Signalling Research, Department of Clinical Medicine, Institute of Molecular Medicine, Dublin 8, Ireland. Tel.: +353-1-896 3350. Fax: +3531- 454 2043. E-mail: verman@tcd.ie

Running head: Tyrosine phosphoproteome of migrating T-cells

Keywords: T-cell migration, LFA-1, ICAM-1, Proteomics

Number of figures: 8 


\section{Abstract}

The ordered, directional migration of T-lymphocytes is a key process during immune surveillance and response. This requires cell adhesion to the high endothelial venules or to the extracellular matrix by a series of surface receptor/ligand interactions involving adhesion molecules of the integrin family including lymphocyte function associated molecule-1 (LFA-1) and intercellular adhesion molecules (ICAMs). Reversible protein phosphorylation is emerging as a key player in the regulation of biological functions with tyrosine phosphorylation playing a crucial role in signal transduction. Thus, the study of this type of post-translational modification at the proteomic level has great biological significance. In this work, phospho-enriched cell lysates from LFA-1-triggered migrating human T-cells were subjected to immunoaffinity purification of tyrosine phosphorylated proteins, mass spectrometric and bioinformatic analysis. In addition to the identification of several well-documented proteins, the analysis suggested involvement of a number of new and novel proteins in LFA-1 induced T-cell migration. This dataset expands the list of the signalling components of the LFA-1 induced phosphotyrosine protein complexes in migrating T-cells that will be extremely useful in the study of their specific roles within LFA-1 associated signalling pathways. Identification of proteins previously not reported in the context of LFA-1 stimulated signal transduction may provide new insights into understanding the LFA-1 signalling networks and aid in the search for new potential therapeutic targets. 


\section{Introduction}

T-lymphocytes are remarkably dynamic cells, continually seeking contacts and connections with their environment. In response to inflammatory signals, T-cells leave the bloodstream by migrating along vascular endothelial surfaces, scanning for a suitable exit point into the tissue.

The contortions necessary for this migration of T-cells require a series of receptor counterreceptor interactions involving adhesion molecules of the integrin family, including the $\alpha \mathrm{L} \beta 2$ integrin known as lymphocyte function associated molecule-1 (LFA-1) (Smith et al., 2007). The interactions between LFA-1 and intercellular adhesion molecule group (ICAMs), in particular ICAM-1, initiate multiple signalling pathways leading to cytoskeletal rearrangements resulting in T-cell migration (Smith et al., 2007; Volkov et al., 2001). The specific role of LFA-1 as a signalling molecule in T-cell migration has previously been studied, with evidence suggesting both tyrosine kinase and serine-threonine kinase involvement in the transduction of the signal for lymphocyte migration.

In this study, we have identified proteins which are tyrosine phosphorylated during Tcell migration following LFA-1 cross-linking. We applied a targeted proteomic approach combined with selective enrichment of phosphotyrosine (pTyr) containing proteins, followed by the mass spectrometry analysis and bioinformatics as outlined in Fig. 1. We further validated a subset of these proteins by Western blotting of lysates of locomotory lymphocytes triggered via LFA-1. We propose that these proteins, including both known and new molecules, expand the previously incomplete list of the signalling components of the LFA-1 signalling pathway. 


\section{Materials and Methods}

\section{Antibodies and reagents}

Anti-LFA-1 antibody (clone SPVL-7) used for the induction of T-cell motility as previously described (Volkov et al., 1998, 2001) was from Monosan (Sanbio, Uden, The Netherlands). Human rICAM-1 was from R\&D Systems (Minneapolis, MN). Goat anti-mouse IgG was from Dako Denmark A/S (Denmark). Mouse monoclonal anti-pTyr antibody (4G10) was from Upstate (Lake Placid, NY). Protein A agarose, goat anti-human IgG (Fc specific), mouse monoclonal anti- $\alpha$-tubulin and anti-talin1 antibodies were from Sigma (St Louis, MO). Mouse monoclonal anti-moesin antibody was from Abcam (Cambridge, MA). Mouse monoclonal anti-L-plastin

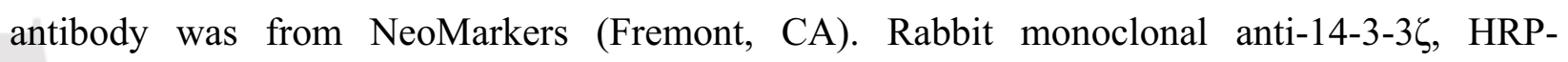
conjugated anti-rabbit and anti-mouse antibodies were from Cell Signalling Technology (Danvers, MA). All the reagents unless attributed specifically were from Sigma (St Louis, MO).

\section{T-cell culture}

The human cutaneous T-lymphoma cell line Hut78 [American Type Culture Collection (ATCC), VA] was cultured as described previously (Volkov et al., 1998). Briefly, cells were cultured in RPMI 1640 medium containing 10\% (v/v) heat inactivated fetal bovine serum (Gibco BRL, Grand Island, NY), L-glutamine $2 \mathrm{mM}$, and antibiotics (penicillin $100 \mathrm{IU} / \mathrm{ml}$, streptomycin 100 $\mu \mathrm{g} / \mathrm{ml}$ ) in a humidified chamber at $37^{\circ} \mathrm{C}$ containing $5 \% \mathrm{CO}_{2}$.

Peripheral blood T-lymphocytes (PBTLs) were isolated from healthy donors as described

(Verma et al., 2008). Briefly, peripheral blood mononuclear cells were prepared using Lymphoprep ${ }^{\circledR}$ (Axis-Shield, Sweden) by density centrifugation. After washing, cells were 
depleted of monocytes by adherence to the tissue culture flask under serum free conditions for 2 $\mathrm{h}$ at $37^{\circ} \mathrm{C}$. Lymphocytes remaining in suspension were aspirated, washed and resuspended $(2 \times$ $10^{6}$ cells per ml) in RPMI 1640 medium supplemented with $10 \%(\mathrm{v} / \mathrm{v})$ heat inactivated fetal bovine serum and $10 \mu \mathrm{g} / \mathrm{ml}$ phytohaemagglutin for 3 days. These cells were maintained in culture for another 7 days in the presence of $20 \mathrm{ng} / \mathrm{ml} \mathrm{IL-2} \mathrm{(Peprotech,} \mathrm{London,} \mathrm{UK)} \mathrm{before}$ harvesting. At this time, T-cell population were deemed pure with $>95 \%$ cells positive for CD3. For migration assays, prior to being loaded into the coated tissue culture plates, 10 days old cultures of PBTLs were washed twice in wash buffer [HEPES $20 \mathrm{mM}(\mathrm{pH} 7.4), \mathrm{NaCl} 140 \mathrm{mM}$, glucose $2 \mathrm{mg} / \mathrm{ml}$ ] and then resuspended in activation buffer [HEPES $20 \mathrm{mM}(\mathrm{pH}$ 7.4), $\mathrm{NaCl} 140$ $\mathrm{mM}$, glucose $2 \mathrm{mg} / \mathrm{ml}, \mathrm{MgCl}_{2} 5 \mathrm{mM}$ and EGTA $\left.1 \mathrm{mM}\right]$.

\section{Induction of T-cell motility}

T-cells were induced to migrate using our well-characterized migration-triggering model system as described (Volkov et al., 2001). Briefly, 6- or 96-well tissue culture plates (flat bottom, $\mathrm{Nunc}^{\mathrm{TM}}$ ), depending on the particular assay type were pre-coated with goat anti-mouse $\operatorname{IgG}$ or mouse anti-human Fc and subsequently incubated with cross-linking monoclonal motility inducing anti-LFA-1 antibody or human rICAM-1. As a control (resting cells), wells were coated with poly-L lysine (cells adhered to this surface without activation) or isotype-matched murine IgG (Dako). Hut78 cells or activated PBTLs were loaded into the coated wells $\left(60 \times 10^{4}\right.$ cells/ well in 6-well plate or $1.0 \times 10^{4}$ cells/well in 96-well plate) and incubated in $5 \% \mathrm{CO}_{2}$ at $37^{\circ} \mathrm{C}$ for indicated time periods depending on the particular experiments. 


\section{Cell lysis and phosphoprotein enrichment}

To obtain cell lysates enriched for phosphoproteins, $\mathrm{BD}^{\mathrm{TM}}$ phosphoprotein enrichment kit (Clontech, Mountain View, CA) was used in accordance with the manufacturer's instructions. The protein content of the cell lysates was determined by Bio-Rad protein assay kit according to manufacturer's instructions (Bio-Rad Laboratories GmbH, München, Germany).

\section{Immunoprecipitation, SDS-PAGE and Western immunoblotting}

The immunoprecipitation was performed as described previously (Verma et al., 2004). Immunoprecipitates or cell lysates were resolved by sodium dodecyl sulphate polyacrylamide gel electrophoresis (SDS-PAGE), Western blotted and probed with indicated antibodies as described or stained with colloidal coomassie blue (Bio-Rad, CA). For Western blotting, the separated proteins were electrophoretically transferred to polyvinylidene fluoride (PVDF) membrane by semi-dry blotting for $1 \mathrm{~h}$. The PVDF membranes were blocked in 5\% non-fat dry milk in PBST $[0.1 \%(\mathrm{v} / \mathrm{v})$ Tween20 in phosphate buffered saline (PBS)] for $1 \mathrm{~h}$ at room temperature. After washing, the blots were incubated with the indicated primary antibodies (diluted according to manufacturer's instructions) overnight at $4^{\circ} \mathrm{C}$ with gentle rocking. After three washing in PBST, the membranes were incubated with appropriate horseradish peroxidase conjugated secondary antibodies for $1 \mathrm{~h}$ at room temperature. The immunoreactive bands were visualized using the enhanced chemiluminescence detection system (Amersham, Arlington Heights, IL) and subsequent exposure to Kodak light sensitive film (Cedex, France). 


\section{In-gel digestion of proteins}

Bands of interest on colloidal coomassie blue stained SDS-PAGE gel were excised and the proteins digested in-gel with trypsin (Promega) after reduction and alkylation, on an Investigator Progest digestion robot (Genomic Solutions Ltd., UK) using standard protocols (Shevchenko et al., 1996).

\section{nLC-ESI-MS/MS}

The resultant peptides were separated on an UltiMate nanoLC (LC Packings, Amsterdam) equipped with a PepMap C18 trap \& column, with a 60 min gradient of increasing acetonitrile concentration, containing $0.1 \%$ formic acid. The eluent was sprayed into a Q-Star XL tandem mass spectrometer (Applied Biosystems, CA) and analysed in Information Dependent Acquisition (IDA) mode, (1 sec of MS followed by 2 × $3 \mathrm{sec}$ MS/MS of the 2 most intense peaks seen by MS. These masses are then excluded from analysis for the next $60 \mathrm{sec}$.

\section{Database searches}

MS/MS data for doubly and triply charged precursor ions was converted to centroid data, without smoothing, using the Analyst QS1.1 mascot.dll data import filter with default settings. The MS/MS data file generated was analysed using the Mascot 2.1 search engine (Matrix Science, London, UK) against MSDB May 2006. The data was searched with tolerances of 0.2 Da for the precursor and fragment ions, trypsin as the cleavage enzyme, one missed cleavage. Three or more matching peptides and a significant probability score $(p<0.05=$ MOWSE score $>$ 50) were required for a secure identity assignment. All MASCOT search results were inspected manually to ensure correct matches. 


\section{In silico analysis}

PhosphoSitePlus ${ }^{\mathrm{TM}}$ : PhosphoSitePlus ${ }^{\mathrm{TM}}$ is a freely accessible on-line proteomics resource devoted to protein phosphorylation plus other commonly studied post-translational modifications, with the goal of providing complete coverage of all published phosphorylation sites. It provides valuable and unique tools for investigating single proteins as well as bulk analyses. Protein sequence was uploaded into the PhosphoSitePlus ${ }^{\mathrm{TM}}$, which indicated presence potential of tyrosine phosphorylation.

\section{Protein ANalysis THrough Evolutionary Relationships (PANTHER): The PANTHER} Classification System (Pathway version 2.5; www.pantherdb.org) is a unique on-line resource that classifies genes by their functions, using published scientific experimental evidence and evolutionary relationships to predict function even in the absence of direct experimental evidence (Thomas et al., 2003). Proteins are classified by expert biologists into families and subfamilies of shared function, which are then categorized by molecular function and biological process ontology terms.

Ingenuity Pathways Analysis (IPA): The IPA software (Ingenuity Systems, Redwood City, CA) is a bioinformatics tool that helps to better understand experimental data in relation to published research by identifying relationships, mechanisms, functions, and pathways of relevance through easy dynamic pathway modeling. It utilizes the Ingenuity ${ }^{\circledR}$ Knowledge Base, which is an updated repository of biological interactions and functional annotations created from millions of individually modeled relationships between proteins, genes, complexes, cells, tissues, drugs, and diseases. To generate biological networks, phosphoproteomics dataset was uploaded into the IPA software as a tab-delimited text file of Gene IDs. IPA protein networks were created and scored 
based on a Fisher's exact test. The score for each network gives an indication of the likelihood of these genes associating into the network by random chance. Each network is displayed as nodes representing genes and edges which represent the interactions between genes. The 'IPA Path Designer' mode was used to generate final network images.

\section{Statistical Analysis}

The data are expressed as mean \pm SEM. For comparison of two groups, $p$-values were calculated by two-tailed unpaired student's t-test. In all cases p-values $<0.05$ was considered to be statistically significant. 


\section{Results}

\section{Locomotory phenotypes in migrating T-cells}

Cross-linking of T-cell surface LFA-1 integrin receptor by mAb mimicking to a certain extent multivalent interactions with natural ligands has been successfully used as a model to study intracellular signalling processes (Volkov et al., 2001, Homasany et al., 2005; Verma et al., 2009). Antibody-induced effects in this case are judged by morphological changes in the cells displaying migratory phenotypes and cytoskeletal rearrangement (Volkov et al., 2001, Verma et al., 2008). In the present study, we used the migration-triggering model system utilizing T-cell lymphoma line Hut78 that displays an activated T-cell phenotype (Volkov et al., 2001; Murphy

et al., 2000). When these cells are exposed to a triggering signal via LFA-1 by immobilized monoclonal antibody specific for its $\alpha$ L-chain, a temporally well defined migrating programme is initiated (Volkov et al., 2001). Cells exhibit striking morphological changes from the beginning of incubation losing their circularity and over the course of $4 \mathrm{~h}$ eventually displaying characteristic migratory phenotype with polarized morphology and long cytoplasmic projections (Fig. 2A). Such morphological changes in T-cells accompany cytoskeletal rearrangement as demonstrated by staining for cytoskeletal proteins tubulin and actin (Fig. 2B).

\section{Tyrosine phosphorylation of proteins in T-cell during LFA-1 induced migration}

Integrin signalling relies on the reversible tyrosine phosphorylation of downstream effector proteins (Clark and Brugge, 1995). In the present study, we set out to identify proteins that are tyrosine phosphorylated after LFA-1 stimulation. Total cell lysates of Hut78 T-cells migrating in response to LFA-1 stimulation harvested at multiple time points were Western blotted for pTyr (Fig. 3). While major changes were not detected in total protein expression profiles of resting $v s$ 
migrating T-cells by 1-D or 2-D gel (data not shown), the pTyr profile showed a time-dependent increase in the number of tyrosine phosphorylated proteins during migration with the highest and sustained level at $30 \mathrm{~min}$ (Fig. 3). Similar results were observed when these cells were immunostained with anti-pTyr and subjected to immunofluorescence microscopy (Supplementary Fig. 1). Thus, a 30 min time point was used for the subsequent experiments. Additionally, High Content Analysis using an IN Cell Analyzer 1000 (GE Healthcare, Buckinghamshire, England)) indicated that an isoflavone compound Genistein (a broad-range tyrosine kinase inhibitor), PP2 (a potent and selective inhibitor of the Src family of tyrosine kinases) or a tyrphostin AG490 (a synthetic selective inhibitor of EGFR that also inhibits Janus kinase family of intracellular protein tyrosine kinases) significantly but not completely inhibited LFA-1 induced T-cell migration (Fig. 4). The fact that other non-pTyr proteins also play important role(s) in T-cell motility may explain this observed effect. Involvement of a number of serine/threonine kinases including protein kinase $\mathrm{C}$ and myosin light chain kinase in $\mathrm{T}$-cell migratory processes has previously been established (Volkov et al., 1998, 2001; Smith et al., 2003). Of note, other tyrosine kinase inhibitors including Herbimycin A (a broad-spectrum inhibitor of non-receptor tyrosine kinase), piceatannol (a Syk-selective tyrosine kinase inhibitor) and a dominant negative ZAP-70 tyrosine kinase have been shown to significantly reduce LFA-1 triggered T-cell migratory processes by our research group (Freeley et al., 2010; Verma et al., 2009; Kelleher et al., 1995) and others (Soede et al., 1998; Wang et al., 2009). Collectively these findings suggest that early tyrosine phosphorylation of proteins is an important event in T-cell migration. 


\section{Isolation of tyrosine phosphorylated proteins}

The most prevalent method for the isolation of tyrosine phosphorylated proteins is by immunoprecipitation with anti-pTyr antibody (Machida et al., 2003), that allows unambiguous identification of proteins by mass-spectrometric analysis. It should be noted, that not all detected proteins are phosphorylated when immunoprecipitation or pull-down methods are used for enrichment, because unmodified proteins can bind to and co-precipitate with phosphoproteins.

The immunoprecipitation of tyrosine phosphorylated proteins had to be optimized. An initial approach to immunoprecipitate $500 \mu \mathrm{g}$ cell lysates with anti-pTyr antibody failed because protein-bands were hardly visible in colloidal coomassie blue stained SDS-polyacrylamide gel (data not shown). The low abundance $(0.05 \%)$ of tyrosine phosphorylated proteins (Machida et al., 2003) highlighted the need to improve the efficiency of immunoprecipitation. Therefore, to efficiently isolate a comprehensive collection of pTyr proteins, an approach to enrich phosphoproteins from whole cell lysates was applied as schematized in Fig. 1. Phospho-enriched proteins from $4 \mathrm{mg}$ cell lysates were immunoprecipitated with anti-pTyr, resolved by SDSPAGE and stained with colloidal coomassie blue for visualization of proteins. As expected, overall tyrosine phosphorylation was enhanced following LFA-1 stimulation by anti-LFA-1 (Fig.

5, Supplementary Fig. 2). A similar tyrosine phosphorylation profile was observed following LFA-1 stimulation by ICAM-1 (Supplementary Fig. 3).

\section{Identification of pTyr containing proteins by nanoLC-MS/MS}

The up-regulated pTyr containing protein that were clearly present in the LFA-1 stimulated cellular lysates (15 bands) were excised from the gel (Fig. 5). These were subjected to mass 
spectrometry analysis as described under "Materials and Methods". A total of 72 proteins were identified by the evaluation of the nanoLC-MS/MS data (Supplementary Table 1).

To further support these results, we searched the NetPhos 2.0 server (www.cbs.dk/services/NetPhos) which predicts tyrosine phosphorylation sites in eukaryotic proteins. The identified proteins were annotated further at PhosphoSitePlus ${ }^{\mathrm{TM}}$ database (www.phosphosite.org), a comprehensive resource of human in vivo phosphorylation sites. The results suggested that most $(91.04 \%)$ of the identified proteins contained at least one tyrosine phosphorylation site (not shown). In addition, each gene was researched by manual examination of published literature using PubMed.

\section{Categorization of the identified proteins}

We used PANTHER (www.pantherdb.org) Gene Ontology ${ }^{\mathrm{TM}}$ to categorize all the identified proteins based on their molecular functions. They were categorized into six different groups as proteins involved in signal transduction, cytoskeletal reorganization, transcriptional regulation, protein biosynthesis, metabolic enzymes and others (Fig. 6). The identities of some of these proteins such as tubulins, actin and talin1 was expected to appear in the analysis, as they were previously reported to be involved in cell migration processes.

\section{Validation of tyrosine phosphorylated proteins by Western immunoblotting}

Next, we sought to validate tyrosine phosphorylation of some of the identified candidate proteins in LFA stimulated migrating T-cells triggered by anti-LFA-1 or ICAM-1. Five target proteins ( $\alpha$ tubulin, talin1, moesin, L-plastin, and 14-3-3६) were selected for further biochemical validation. For this purpose, serum starved Hut78 cells or PBTLs isolated from healthy volunteers were 
incubated with immobilized anti-LFA-1 or ICAM-1 for 30 min and lysed. Cell lysates were then immunoprecipitated separately with anti-pTyr or anti-IgG (isotype control) and probed with antibodies to the selected five proteins. As can be seen in Fig. 7, the Western blot analysis using both Hut78 cells as well as primary T-cells was consistent with the results from mass spectrometry for all of the proteins tested (Fig. 7A,B).

\section{In-silico protein network analysis of identified tyrosine phosphoproteome}

Ingenuity Pathways Analysis was used to interrogate biological networks associated with identified tyrosine phosphoproteome data obtained from migrating T-cells. Gene IDs of all the 72 identified proteins were uploaded to Ingenuity software, of which 68 could be mapped using Ingenuity's knowledge database. IPA of these 68 genes resulted in the generation of four networks of protein and/or gene associations. The top three scoring networks are shown in Supplementary Fig. 4. These networks are related to a number of functions including immune response, cell movement, cell morphology, cell cycle and gene expression. Conditions associated with the networks include cancer, gastrointestinal disease and immunological diseases.

The mapped genes were significantly associated with a number of canonical pathways that are pre-defined in IPA. Three of the top pathways are involved in cell migration and include integrin signalling $(p=3.51 \mathrm{E}-06)$, leukocyte extravasation signalling $(p=3.33 \mathrm{E}-05)$ and cytoskeleton rearrangement ( $p=7.36 \mathrm{E}-05$ ). As we were principally interested in LFA-1 integrin signalling, a network was generated by growing out the canonical pathway using the build function in IPA. The nodes added were restricted to proteins within our list and those which are directly interacting with each other. Some additional nodes such as cofilin1, STAT3 and stathmin previously demonstrated to be involved in LFA-1 signalling (Verma et al., 2009; Burkhardt et al., 2008) were subsequently added to further enrich the network (Fig. 8). This 
network demonstrates how proteins within our list interact with key components of LFA-1 integrin signalling. Of the genes in the network, $14-3-3 \xi$ represents the most connected node having a total of 11 edges, suggesting crucial importance of this protein in regulating lymphocyte migration.

Based on these observations, it is tempting to speculate that the identified proteins may play important role(s) in the LFA-1 signal transduction cascades leading to cytoskeletal rearrangement and T-cell motility. Future studies are required to determine the functional significance of Tyr phosphorylation of the novel pTyr species in T-cell migration. 


\section{Discussion}

Integrin receptor engagement in T-cells activates several proteins by tyrosine phosphorylation that initiates signalling cascades and contributes to the assembly of a 'signalosome', a multiprotein complex including various enzymes, their substrates and scaffold/adapter proteins. The identification of proteins undergoing tyrosine phosphorylation in response to LFA-1 integrin stimulation is essential for understanding the molecular mechanisms and relevant signalling pathways that regulate T-cell migration. Rapid progress in mass spectrometric technology in the past few years has allowed analysis and identification of proteins undergoing such posttranslational modifications with unprecedented levels of sensitivity. Technologies for selective enrichment of phosphoproteins and availability of protein sequence data have further improved the phosphoproteomic studies, particularly the identification of tyrosine phosphorylated proteins.

In the present study, by selective immunoprecipitation of phosphotyrosine containing proteins coupled with mass-spectrometric analysis, we identified several proteins and their associated complexes involved in LFA-1 induced T-cell migration. A total of 72 proteins were identified as involved in LFA-1-triggred T-cell migration, and we propose these as components of the LFA-1 signalling pathway. We identified several proteins novel to LFA-1 signalling such as $14-3-3 \zeta$. Using the bioinformatics software 'PANTHER', the identified proteins were categorized into six broad groups based on their molecular functions. Here, we discuss the relevance of some of the identified proteins.

1. Cell signalling proteins. We identified a range of cell signalling proteins including GTP binding protein Rac2, PARP-1, prohibitin, testin, guanine nucleotide binding protein, nucleolin,

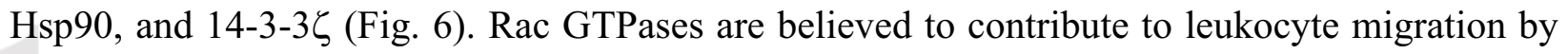
integrating signals from cell surface receptors to the cytoskeleton, in particular Rac2 has recently 
been identified a key molecule regulating LFA-1/ICAM-1 interactions in B lymphocytes (Arana et al., 2009). Rac GTPases interact with several downstream effectors to trigger cytoskeletal reorganization. One of the many effectors of Rac comprises of an evolutionary conserved family of serine/threonine protein kinases, PAK or p21-activated kinase (Hofman et al., 2004). PAK kinases are strongly implicated in the regulation of cytoskeletal architecture (Hofman et al., 2004), focal adhesion contacts, cell motility and lymphocyte chemotaxis (Weiss-Haljiti et al., 2004; Volinsky et al., 2006). PAK1 has been shown to interact with a number of migrationrelated proteins including profilin, cofilin, importin, 14-3-3, paxilin, tubulins, actin, dynactin, dynanin, Grb2, PAK-interacting exchange factor PIX etc. (Hofmann et al., 2004; Mayhew et al., 2006) providing a possible bridging point with the LFA-1 interactome. Nucleolin, a ubiquitous nucleolar phosphoprotein, has recently reported to be a signal transducing P-selectin binding protein (Reyes-Reyes and Akiyama, 2008). Functional blockage or down-regulation of nucleolin expression significantly inhibited endothelial cell migration and prevented tubule formation (Huang et al., 2006). Nucleolin has been shown to undergo tyrosine phosphorylation and formation of signalling complexes with PI3-K and $\mathrm{p} 38$, indicating its potential involvement in signal transduction pathways that regulate cell adhesion and spreading (Reyes-Reyes and Akiyama, 2008). The involvement of nucleolin at multiple steps suggests that it could play a key role in this highly integrated process of T-cell migration. Hsp90, identified in this study, has been demonstrated to be important for tumor cell motility and invasion (Tsutsumi et al., 2008). Hsp90 has recently been shown to be essential for Jak-STAT signalling (Schoof et al., 2009), which is

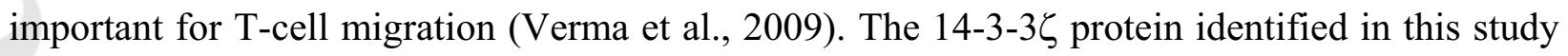
has been demonstrated to interact and regulate phosphatidylinositol 3-kinase (Bonnefoy-Berard et al., 1995), Tau (Chun et al., 2004; Yuan et al., 2004; Li and Paudel, 2007), 3BP2/SH3BP2 
adaptor protein (Foucault et al., 2003) and $\operatorname{PKC}(\beta)$ (Robinson et al., 1994; Kim et al., 2005; Aitken, 2006; Meller et al., 1996), an enzyme crucial for cytoskeletal rearrangements in lymphocyte migration (Volkov et al., 1998, 2001). On the basis of these functions and our previous reports (Volkov et al., 1998, 2001; Fanning et al., 2005; Verma et al., 2008), we surmised that $14-3-3 \zeta$ might also be involved in T-cell migration and selected this protein for further validation. Our ongoing focused experiments will further establish the physiological functions of $14-3-3 \zeta$ in T-cell migration.

2. Cytoskeletal proteins. The major changes that occur during T-cell migration following LFA1 stimulation is the rearrangement of cytoskeleton and associated proteins (Volkov et al., 1998, 2001; Verma et al., 2008; Miletic et al., 2003). In this study several cytoskeletal proteins including tubulins, actin, talin1, moesin, L-plastin, and LASP1 were found to be tyrosine phosphorylated in migrating T-cells (Fig. 6). Some of these proteins are known to be tyrosine phosphorylated in response to a range of stimulus (Ley et al., 1994; Gunderson and Cook, 1999; Meyer et al., 1998; Schreiber et al., 1998). Tyrosine phosphorylation of ERM (Ezrin/Radixin/Moesin) family of proteins has previously been reported (Tsukita et al., 1997). Moesin has been shown to undergo tyrosine phosphorylation in human platelets by Arachidonic acid stimulation (Meyer et al., 1998). Recently, tyrosine phosphorylation of Ezrin at Y145 and Y353 has been reported in cell adhesion-based signalling and T-cell activation (Srivastava et al., 2005; Shaffer et al., 2009). These pTyr sites are conserved in both Ezrin and Moesin (Shaffer et al. 2009). Tyrosine phosphorylation of tubulin observed in this study was similar to that previously reported, though induced by different stimulus (Ley et al., 1994). L-Plastin, a $\mathrm{Ca}^{2+}$ regulated actin-binding cytoskeletal protein, identified in this study has recently been reported by our research group and others to be involved in LFA-1 signal transduction (Foran et al., 2006; 
Jones et al., 1998). Talin1 is essential for the stability and formation of the LFA-1 zone in migrating T-lymphocytes (Smith et al., 2005; Bertagnolli et al., 1993; Martel et al., 2001).

3. Transcription regulator. Proteins involved in transcription regulation were also identified. These include DNA topoisomerase I, FACT, GTF2I, SSRP1, ErbB3 binding protein1, minichromosome maintenance proteins 2 and 5 (Fig. 6). DNA topoisomerase I is known to undergo tyrosine phosphorylation by cAbl tyrosine kinase (Yu et al., 2004).

4. RNA maturation, protein biosynthesis. We observed tyrosine phosphorylation of several proteins involved in RNA maturation and protein synthesis including ribosomal proteins, RNA helicases, hnRNP $\mathrm{H}$ etc. (Fig. 6). This suggests an early induction of protein biosynthesis programme in migrating T-cells.

5. Metabolic enzymes. A large number of proteins involved in energy metabolism including mitochondrial enzymes undergoing tyrosine phosphorylation were identified in migrating T-cells (Fig. 6). Although this study did not directly analyze activity of the observed enzyme, we speculated that phosphorylation of these enzymes may mediate alteration of intermediary metabolisms induced by LFA-1 in migrating T-cells. Adenine nucleotide translocator 2 (ANT2) plays a crucial role in cell bioenergetics by catalyzing ADP and ATP exchange across the mitochondrial inner membranes (Chevrollier et al., 2005). ANT2 has recently been proposed for ATP uptake in cancer cells, in conjugation with hexokinase II and $\beta$ subunit of mitochondrial ATP synthase, in the mitochondrial inner membrane potential maintenance and in the aggressiveness of cancer cells (Chevrollier et al., 2005).

6. Others. Few other proteins including molecular chaperones such as histones also coprecipitated with anti-pTyr in migrating T-cells (Fig. 6). A role the nuclear protein Histone H1 on signalling pathways in CD4+ T-cells has also been reported (Hsu et al., 2008). 


\section{Conclusion}

In conclusion, utilizing a targeted phosphoproteome analysis approach, we were able for the first time to obtain insights into components of LFA-1 induced phosphotyrosine protein complexes in migrating T-cells. We propose that these proteins, including several known and new molecules, expand the previously incomplete list of the signalling components of the LFA-1 signalling pathway. While some tyrosine phosphorylated proteins are not detected and quantitative information about the up-regulated proteins could not be obtained using this approach, we present a comprehensive dataset of known and novel players in the LFA-1 triggered signalling pathways in migrating T-cells. The information about the proteins that are subject to tyrosine phosphorylation can be extremely useful in the study of their specific roles within LFA-1 associated signalling pathways. These findings will broaden our view on tyrosine phosphorylation and protein-protein interaction, the two major mechanisms for receptor mediated signal transduction. The detailed relationship between LFA-1 signalling and tyrosine phosphorylation of identified proteins will require further investigation. Identification of proteins previously not reported in the context of LFA-1 stimulated signal transduction may provide new insights into understanding the LFA-1 signalling networks and aid in the search for new potential therapeutic targets. 


\section{Acknowledgements}

This work was supported by a Grant from the Higher Education Authority (HEA) of Ireland under the Program for Research in Third Level Institutions (PRTLI) Cycle 3 and by the Health Research Board of Ireland. We thank the Wellcome Trust for funding the mass spectrometer. 


\section{Literature Cited}

Aitken A. 2006. 14-3-3 proteins: a historic overview. Semin Cancer Biol 16:162-172.

Arana E, Vehlow A, Harwood NE, Vigorito E, Henderson R, Turner M, Tybulewicz VLJ, Batista FD. 2009. Activation of the small GTPase Rac2 via the B cell receptor regulates B cell adhesion and immunological-synapse formation. Immunity 28:88-99.

Bertagnolli ME, Locke SJ, Hensler ME, Bray PF, Beckerle MC. 1993. Talin distribution and phosphorylation in thrombin-activated platelets. J Cell Sci 106:1189-1199.

Bonnefoy-Berard N, Liu YC, Willebrand MV, Sung A, Elly C, Mustelin T, Yoshida H, Ishizaka K, Altman A. 1995. Inhibition of phosphatidylinositol 3-kinase activity with 14-3-3 proteins in T cells. Proc Natl Acad Sci USA 92:10142-10146.

Burkhardt JK, Carrizosa E, Shaffer MH. 2008. The actin cytoskeleton in T cell activation. Ann Rev Immunol 152:576-584.

Chevrollier A, Loiseau D, Stepien G. 2005. What is the specific role of ANT2 in cancer cells? Med Sci (Paris) 21:156-161.

Chun J, Kwon T, Lee EJ, Kim CH, Han YS, Hong SK, Hyun S, Kang S. 2004. 14-3-3 protein mediates phosphorylation of microtubule-associated protein tau by serum and glucocorticoid-induced protein kinase1. Mol Cell 18:360-368.

Clark EA, Brugge JS. 1995. Integrins and signal transduction pathways: the road taken. Science 268:233-239. 
Fanning A, Volkov Y, Freely M, Kelleher D, Long A. 2005. CD44 cross-linking induces protein kinase C-regulated migration of human T lymphocytes. Int Immunol 17:449-458.

Foran E, McWilliam P, Kelleher D, Croke DT, Long A. 2006. The leukocyte protein L-plastin induces proliferation, invasion and loss of E-cadherin expression in colon cancer cells. Int J Cancer 118:2098-2104.

Foucault I, Liu YC, Bernard A, Deckert M. 2003. The chaperone protein 14-3-3 interacts with 3BP2/SH3BP2 and regulates its adapter function. J Biol Chem 278:7146-7153.

Freeley M, Bakos G, Davies A, Kelleher D, Long A, Dunican DJ. 2010. A high-content analysis toolbox permits dissection of diverse signaling pathways for T lymphocyte polarization. $\mathrm{J}$ Biomol Screen 15:541-555.

Gunderson GG, Cook TA. 1999. Microtubule and signal transduction. Curr Opin Cell Biol 11:81-94.

Hofmann C, Sphepelev M, Chernoff J. 2004. The genetics of Pak. J Cell Sci 117:4343-4354.

Homasany BSEDE, Volkov Y, Takahashi M, Ono Y, Keryer G, Delouvee A, Looby E, Long A, Kelleher D. 2005. The scaffolding protein CG-NAP/ AKAP450 is a critical integrating component of the LFA-1-induced signaling complex in migratory $\mathrm{T}$ cells. J Immunol 175:7811-7818.

Hsu LW, Chen CL, Nakano T, Lai CY, Chiang KC, Lin YC, Kao YH, Chen SH, Goto T, Sung WC, Yang CH, Cheng YF, Jawan B, Chiu KW, Goto S. 2008. The role of a nuclear 
protein, histone H1, on signalling pathways for the maturation of dendritic cells. Clin Exp Immunol 152:576-584.

Huang Y, Shi H, Zhou H, Song X, Yuan S, Luo Y. 2006. The angiogenic function of nucleolin is mediated by vascular endothelial growth factor and nonmuscle myosin. Blood 107:35643571.

Jones SL, Wang J, Truck CW, Brown EJ. 1998. A role for the actin-bundling protein L-plastin in the regulation of leukocyte integrin function. Proc Natl Acad Sci USA 95:9331-9336.

Kelleher D, Murphy A, Feighery C, Casey EB. 1995. Leukocyte function-associated antigen 1 (LFA-1) and CD44 are signalling molecules for cytoskeleton-dependent morphological changes in activated T cells. J Leukocyte Biol 58:539-546.

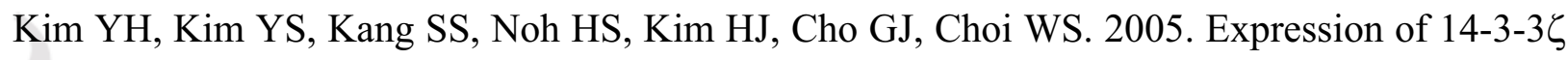
and interaction with protein kinase $\mathrm{C}$ in the rat retina in early diabetes. Diabetologia 48:1411-1415.

Ley SC, Verbi W, Pappin DJC, Druker B, Davies AA, Crumpton MJ. 1994. Tyrosine phosphorylation of $\alpha$-tubulin in human T lymphocytes. Eur J Immunol 24:99-106.

Li T, Paudel HK. 2007. 14-3-3 $\zeta$ facilitates GSK $\beta$-catalyzed tau phosphorylation in HEK-293 cells by a mechanisms that requires phosphorylation of GSK $\beta$ on $\operatorname{Ser}^{9}$. Neurosci Lett 414:203-208.

Machida K, Mayer BJ, Nollau P. 2003. Profiling the global tyrosine phosphorylation state. Mol Cell Proteomics 2:215-233. 
Martel V, Racaud-Sultan C, Dupe S, Marie C, Paulher F, Galmiche A, Block MR, Albiges-Rizo C. 2001. Conformation, localization and integrin binding of Talin depend on its interaction with phosphoinositides. J Biol Chem 276:21217-21227.

Mayhew MW, Webb DJ, Kovalenko M, Whitmore L, Fox JW, Horwitz AF. 2006. Identification of protein networks associated with the PAK1-ßPIX-GIT1-Paxillin signalling complex by mass spectrometry. J Proteome Res 5:2417-2423.

Meller N, Liu YC, Collins TL, Bonnefoy-Berard N, Baier G, Isakov N, Altman A. 1996. Direct interaction between protein kinase $\mathrm{C}$ theta )PKC theta) and 14-3-3 tau in T cells: 14-3-3 overexpression results in inhibition of PKC theta translocation and function. Mol Cell Biol 16:5782-5791.

Meyer T, Uher T, Schwartz P, Buchwald AB. 1998. Tyrosine phosphorylation of moesin in Archidonic acid-stimulated human platelets. J Thromb Thrombolysis 6:117-124.

Miletic AV, Swat M, Fujikawa K, Swart W. 2003. Cytoskeletal remodeling in lymphocyte activation. Curr Opin Immunol 15:261-268.

Murphy A, Long A, Volkov Y, Kelleher D. 2000. Cross-linking of LFA-1 induces secretion of macrophage inflammatory protein (MIP)-1 $\alpha$ and MIP- $1 \beta$ with consequent directed migration of activated lymphocytes. Eur J Immunol 30:3006-3011.

Reyes-Reyes EM, Akiyama SK. 2008. Cell-surface nucleolin is a signal transducing P-selectin binding protein for human colon carcinoma cells. Exp Cell Res 314:2212-2233. 
Robinson K, Jones D, Patel Y, Martin H, Madrazo J, Martin S, Howell S, Elmore M, Finnen MJ, Aitken A. 1994. Mechanism of inhibition of protein kinase C by 14-3-3 isoforms. 14-3-3 isoforms do not have phospholipase A2 activity. Biochem J 299:853-861.

Schoof N, von Bonin F, Trümper L, Kube D. 2009. HSP90 is essential for Jak-STAT signalling in classical Hodgkin Lymphoma cells. Cell Commun Signal (in press; doi:10.1186/1478$811 \mathrm{X}-7-17)$

Schreiber V, Moog-Lutz C, Regnier CH, Chenard MP, Boeuf H, Vonesch JL, Tomasetto C, Rio MC. 1998. Lasp-1, a novel type of actin-binding protein accumulating in cell membrane extension. Mol Med 4:675-687.

Shaffer MH, Dupree RS, Zhu P, Saotome I, Schmidt RF, McClatchey AI, Freedman BD, Burkhardt JK. 2009. Ezrin and moesin function together to promote T cell activation. J Immunol 182:1021-1032.

Shevchenko A, Wilm M, Vorm O, Mann M. 1996. Mass spectrometric sequencing of proteins from silver stained polyacrylamide gels. Anal Chem 68:850-858.

Smith A, Bracke M, Leitinger B, Porter JC, Hogg N. 2003. LFA-1-induced T cell migration on ICAM-1 involves regulation of MLCK-mediated attachment and ROCK-dependent detachment. J Cell Sci 116:3123-3133.

Smith A, Carrasco YR, Stanley P, Kieffer N, Batista FD, Hogg N. 2005. A talin-dependent LFA1 focal zone is formed by rapidly migrating T lymphocytes. J Cell Biol 170:141-151. 
Smith A, Stanely P, Jones K, Sevensson L, McDowall A, Hogg N. 2007. The role of the integrin LFA-1 in T-lymphocyte migration. Immunological Rev 218:135-146.

Soede RDM, Wijnands YM, Kouteren-Cobzaru IV, Roos E. 1998. ZAP-70 Tyrosine kinase is required for LFA-1-dependent T cell migration. J Cell Biol 142:1371-1379.

Srivastava J, Elliott BE, Louvard D, Arpin M. 2005. Src-dependent ezrin phosphorylation in adhesion-mediated signaling. Mol Biol Cell 16:1481-1490.

Thomas PD, Campbell MJ, Kejariwal A, Mi H, Karlak B, Daverman R, Diemer K, Muruganujan A, Narechania A. 2003. PANTHER: a library of protein families and subfamilies indexed by function. Genome Res 13:2129-2141.

Tsukita S, Yonemura S, Tsukita S. 1997. ERM (ezrin/radixin/moesin) family: from cytoskeleton to signal transduction. Curr Opin Cell Biol 9:70-75.

Tsutsumi S, Scroggins B, Koga F, Lee MJ, Trepel J, Felts S, Carreras C, Neckers L. 2008. A small molecule cell-impermeant Hsp90 antagonist inhibits tumor cell motility and invasion. Oncogene 27:2478-2487.

Verma NK, Dempsey E, Conroy J, Olwell P, Mcelligott AM, Davies AM, Kelleher D, Butini S, Campiani G, Williams DC, Zisterer DM, Lawler M, Volkov Y. 2008. A new microtubule-targeting compound PBOX-15 inhibits T-cell migration via posttranslational modifications of tubulin. J Mol Med 86:457-469. 
Verma NK, Dourlat J, Davies AM, Long A, Kelleher D, Liu WQ, Garbay C, Volkov Y. 2009. STAT3-stathmin interactions control microtubule dynamics in migrating T-cells. J Biol Chem 284:12349-12362.

Verma NK, Singh J, Dey CS. 2004. PPAR $\gamma$ expression modulates insulin sensitivity in C2C12 skeletal muscle cells. Br J Pharmacol 143:1006-1013.

Volinsky N, Gantman A, Yablonski D. 2006. A Pak- and Pix-dependent branch of the SDF-1 $\alpha$ signalling pathway mediates $\mathrm{T}$ cell chemotaxis across restrictive barriers. Biochem $\mathrm{J}$ 397:213-222.

Volkov Y, Long A, Kelleher D. 1998. Inside the crawling T cell: leukocyte function-asociated antigen-1 cross-linking is associated with microtubule-directed translocation of protein kinase $\mathrm{C}$ isozymes $\beta(\mathrm{I})$ and $\delta$. J Immunol 161:6487-6495.

Volkov Y, Long A, McGrath S, Eidhin DNi, Kelleher D. 2001. Crucial importance of PKC- $\beta(\mathrm{I})$ in LFA-1-mediated locomotion of activated T cells. Nat Immunol 2:508-514.

Wang H, Wei B, Bismuth G, Rudda CE. 2009. SLP-76-ADAP adaptor module regulates LFA-1 mediated costimulation and T cell motility. Proc Natl Acad Sci 106:12436-12441.

Weiss-Haljiti C, Pasquali C, Ji H, Gillieron C, Chabert C, Curchod ML, Hirsch E, Ridley AJ, van Huijsduijnen RF, Camps M, Rommel C. 2004. Involvement of phosphoinositide 3-kinase $\gamma$, Rac, and PAK signaling in chemokine-induced macrophage migration. J Biol Chem 279:43273-43284. 
Yu D, Khan E, Khaleque MA, Lee J, Laco G, Kohlhagen G, Kharbanda S, Cheng YC, Pommier Y, Bharti A. 2004. Phosphorylation of DNA topoisomerase I by the c-Abl tyrosine kinase confers camptothecin sensitivity. J Biol Chem 279:51851-51861.

Yuan ZF, Agarwal-Mawal A, Paudel HK. 2004. 14-3-3 binds to and mediates phosphorylation of microtubule-associated tau protein by Ser ${ }^{9}$-phosphorylated glycogen synthase kinase $3 \beta$ in the brain. J Biol Chem 279:26105-26114. 


\section{Figure Legends}

Fig. 1. Experimental schema used for enrichment of phosphotyrosine proteins and their identification. Resting or migrating Hut78 T-cells were lysed, enriched for phosphoproteins followed by immunoaffinity purification of tyrosine phosphorylated proteins and resolved by SDS-PAGE. Proteins bands showing increased intensity were excised and subjected to massspectrometric analysis for identification.

Fig. 2. Time-dependent changes in T-cell morphology and cytoskeletal systems in response to a locomotory signalling via LFA-1. A: Hut78 cells were incubated on poly L-lysine (0 min) or anti-LFA-1 coated 96-well plates $\left(10^{4}\right.$ cells/well) for 5, 10, 15, 30 or $240 \mathrm{~min}$ and photographed using Nikon phase contrast microscope (40X). B: Resting or LFA-1 stimulated migrating Hut78 cells were immunostained for $\alpha$-tubulin (green), actin (red) and nuclei (blue) and visualized by a Zeiss LSM 510 fluorescence confocal microscope (63X oil). At least 20 microscopic fields under each conditions were photographed and representative figures are shown. Results shown are representative of three independent experiments.

Fig. 3. Phosphotyrosine protein profile of migrating T-cells. Serum starved Hut78 cells (0 min) were incubated on anti-LFA-1 coated plates for 5, 10, 15, 30 or $240 \mathrm{~min}$ and lysed. Cell lysates (10 $\mu \mathrm{g}$ each) were separated by SDS-PAGE (10\% gel) and after Western blotting probed with anti-pTyr antibody; $\alpha$-Tubulin was used as a loading control. Results shown are representative of three independent experiments.

Fig. 4. Effect of tyrosine kinase inhibition on T-cell migration. Serum starved Hut78 cells were pre-treated with Genistein $(25 \mu \mathrm{M})$, PP2 $(10 \mu \mathrm{M})$ or AG490 $(10 \mu \mathrm{M})$ for 30 min and then incubated on anti-LFA coated 96-well plate for $4 \mathrm{~h}$. T-cell migratory phenotypes were analyzed 
using HCA by quantifying cell $1 /$ form factor (form factor $=4 \pi$ area/perimeter ${ }^{2}$ is the measure of roundness). Data is mean \pm SEM of three independent experiments performed in triplicates. ${ }^{*} \mathrm{p}<0.05$

Fig. 5. SDS-PAGE of differentially tyrosine-phosphorylated proteins in migrating T-cells. Serum starved Hut78 cells were stimulated by incubating on anti-LFA-1 coated plates for $30 \mathrm{~min}$. Cells were then lysed and cleared cell lysates (4 mg each) were enriched for phosphoproteins followed by immunoprecipitation using anti-pTyr. The immune complexes were resolved by SDS-PAGE $(10 \%$ gel) and visualized by colloidal coomassie blue staining. Bands of interest, as indicated, were excised and processed for subsequent mass spectrometric analysis.

Fig. 6. Summary of tyrosine phosphoproteomics data. Tyrosine phosphorylated proteins identified from anti-pTyr affinity purification and mass spectrometric analysis were categorized based on their molecular functions and listed. The numbers and percentages of proteins under each category are shown in parentheses.

Fig. 7. Validation of MS/MS data for selected proteins by Western blot analysis. Serum starved Hut78 cells (A) or PBTLs isolated from healthy volunteers (B) were incubated on anti-LFA-1 or ICAM-1 coated plates for $30 \mathrm{~min}$ and lysed. Cell lysates (500 $\mu \mathrm{g}$ each) were immunoprecipitated with anti-pTyr (IP: pTyr) or IgG (isotype control; $I P$ : $I g G$ ). Immunoprecipitates and whole cell lysates (used as a control $20 \mu \mathrm{g}$ each; $W C L$ ) were Western blotted (WB) and probed with anti- $\alpha-$

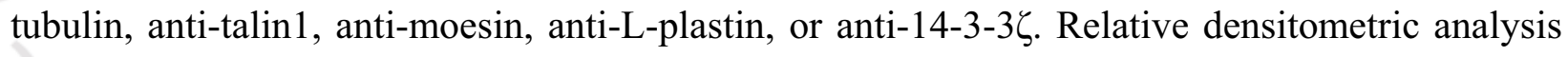
of the individual band is presented. Data are mean \pm SEM. of three independent experiments. ${ }^{*} \mathrm{p}<0.05$ with respect to corresponding controls. 
Fig. 8. Key components of IPA network of interactions in LFA-1 integrin signalling pathway. A network was generated using IPA by combining the canonical integrin signalling pathway. Each node represents a gene and their shape indicates their functional classes as shown in the figure key. Red nodes, proteins that undergo tyrosine phosphorylation following LFA-1 activation; grey nodes, key components within the canonical LFA-1 integrin signalling pathway; clear nodes, components added to extend the network; edges, direct interactions between nodes.

Supplementary Fig. 1. Phosphotyrosine immunostaining of Hut78 cells during LFA-1 induced migration. Serum starved Hut78 cells were incubated on poly-L lysine (0 min) or anti-LFA-1 coated plates for $5,10,15,30,240$ min and fixed. After permeablization with $0.5 \%$ Triton X100, cells were immunostained for phosphotyrosine (red) and $\alpha$-tubulin (green). Nuclei were stained with Hoechst (blue). Cells were visualized by Nikon florescence microscope with 40X objective lens. At least 20 microscopic fields were photographed and representative figures are shown. Results shown are representative of three independent experiments.

Supplementary Fig. 2. SDS-PAGE of differentially tyrosine-phosphorylated proteins in migrating T-cells stimulated by anti-LFA-1. Serum starved Hut78 cells were incubated on antiLFA-1 or isotype-matched murine IgG (Isotype control) coated plates for $30 \mathrm{~min}$. Cells were then lysed and cleared cell lysates (4 mg each) were enriched for phosphoproteins followed by immunoprecipitation using anti-pTyr. Cellular lysates and immune complexes were resolved by SDS-PAGE (10\% gel) and visualized by colloidal coomassie blue staining. Lane 1: Protein marker (Biorad), Lane 2: Whole cell lysate from resting cells (10 $\mu \mathrm{g})$; Lane 3: Whole cell lysate from migrating cells $(10 \mu \mathrm{g})$; Lane 4: Immunoprecipates of cells harvested from isotype-matched murine IgG coated plates; Lane 5: Immunoprecipates of resting cells; Lane 6: Immunoprecipates of migrating cells harvested from anti-LFA coated plates. 
Supplementary Fig. 3. SDS-PAGE of tyrosine-phosphorylated proteins in LFA-1 stimulated migrating T-cells. Serum starved Hut78 cells were incubated on anti-LFA-1 or rICAM-1 coated plates for $30 \mathrm{~min}$. Cells were then lysed and cleared cell lysates (4 mg each) were enriched for phosphoproteins followed by immunoprecipitation using anti-pTyr. The immune complexes were resolved by SDS-PAGE (10\% gel) and visualized by colloidal coomassie blue staining.

Supplementary Fig. 4. Ingenuity Pathways Analysis networks of tyrosine phosphorylated proteins in migrating T-cells. Top three networks are shown. Network 1 has a score of 65 and contains 26 proteins form the list. Networks 2 and 3 have 17 and 10 focus molecules respectively. Shaded nodes indicate proteins within our list, non-shaded nodes indicate components added to enrich the network. Straight lines indicate direct interactions and dashed lines indicate indirect interactions.

Supplementary Table 1. A list of proteins identified by nLC-ESI-MS/MS shown in Fig. 5. 
Figure 1

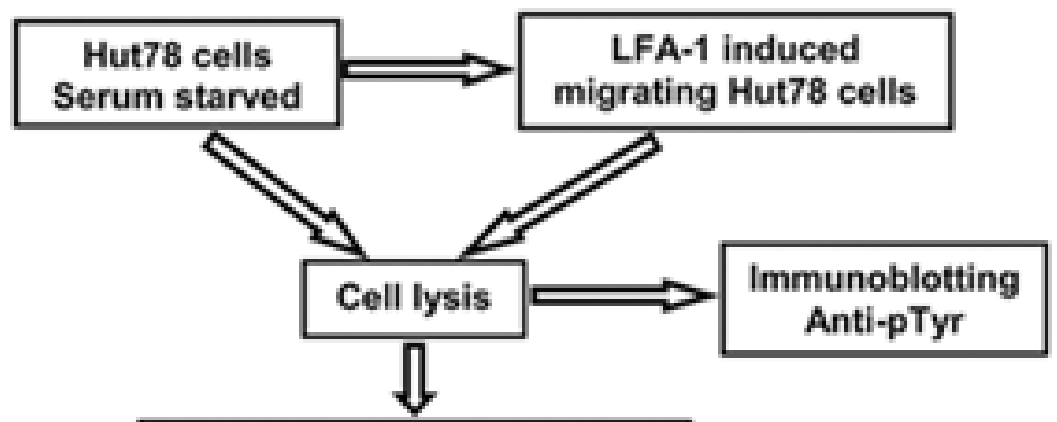

Phosphoprotein enrichment

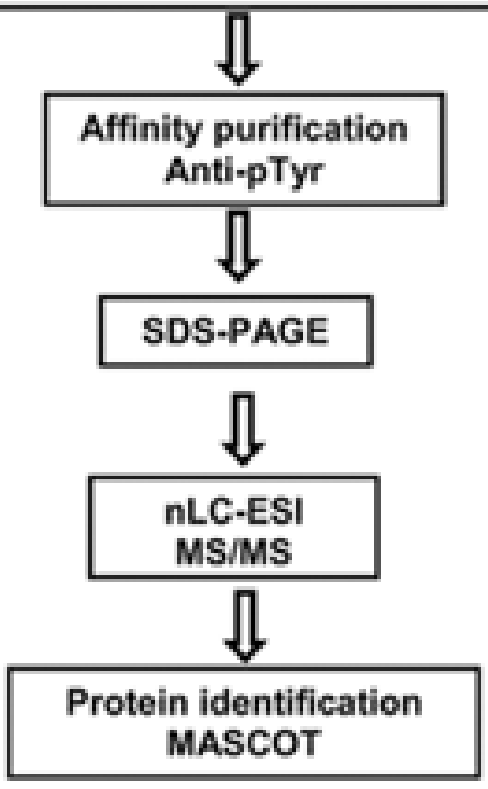


Figure 2

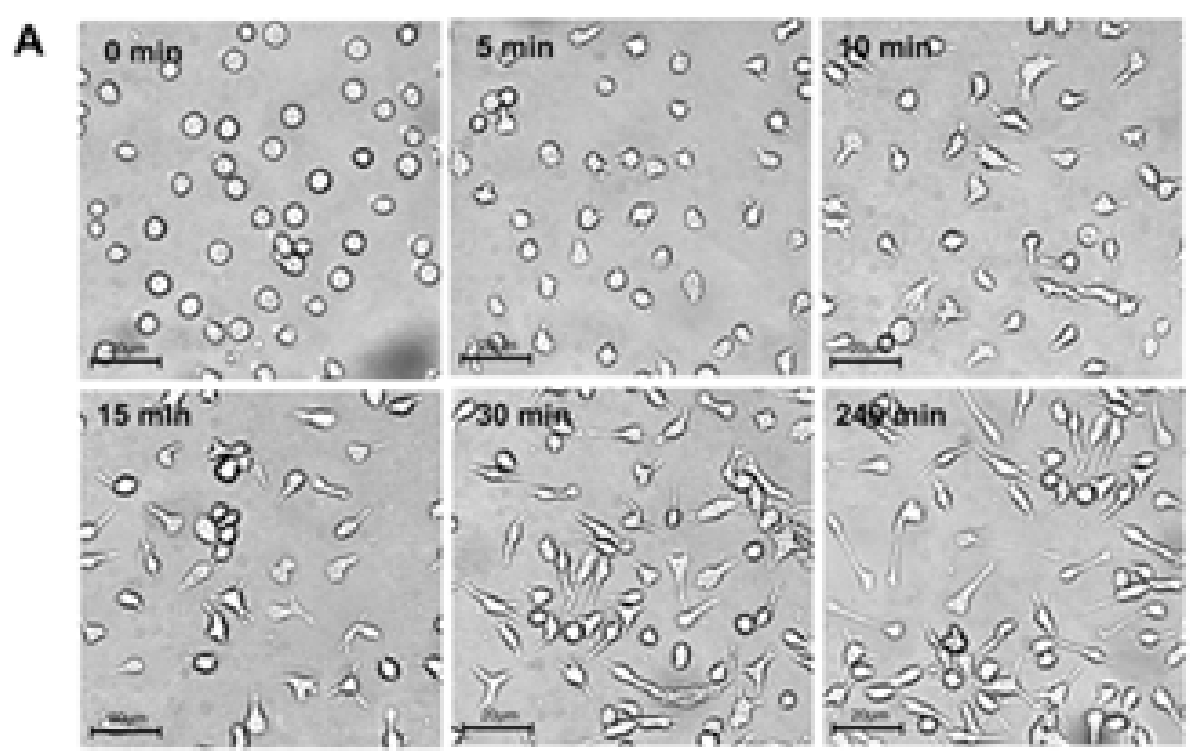

B Resting Hut78 cells

LFA-1 stimulated migrating Hut78 cells
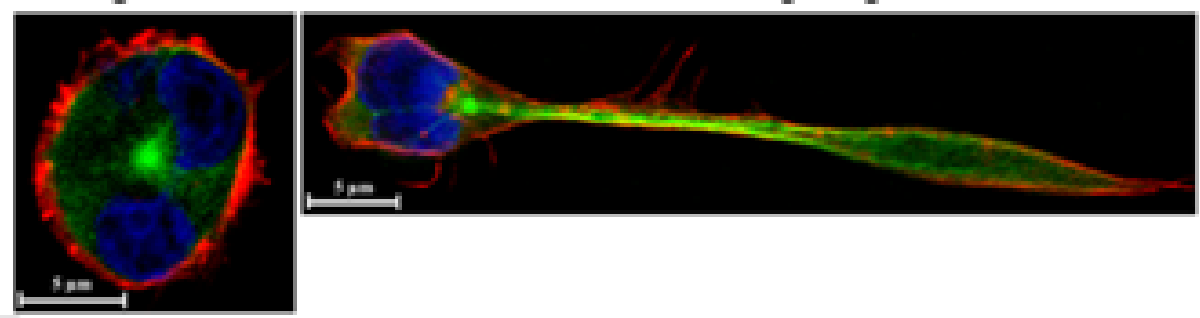
Figure 3

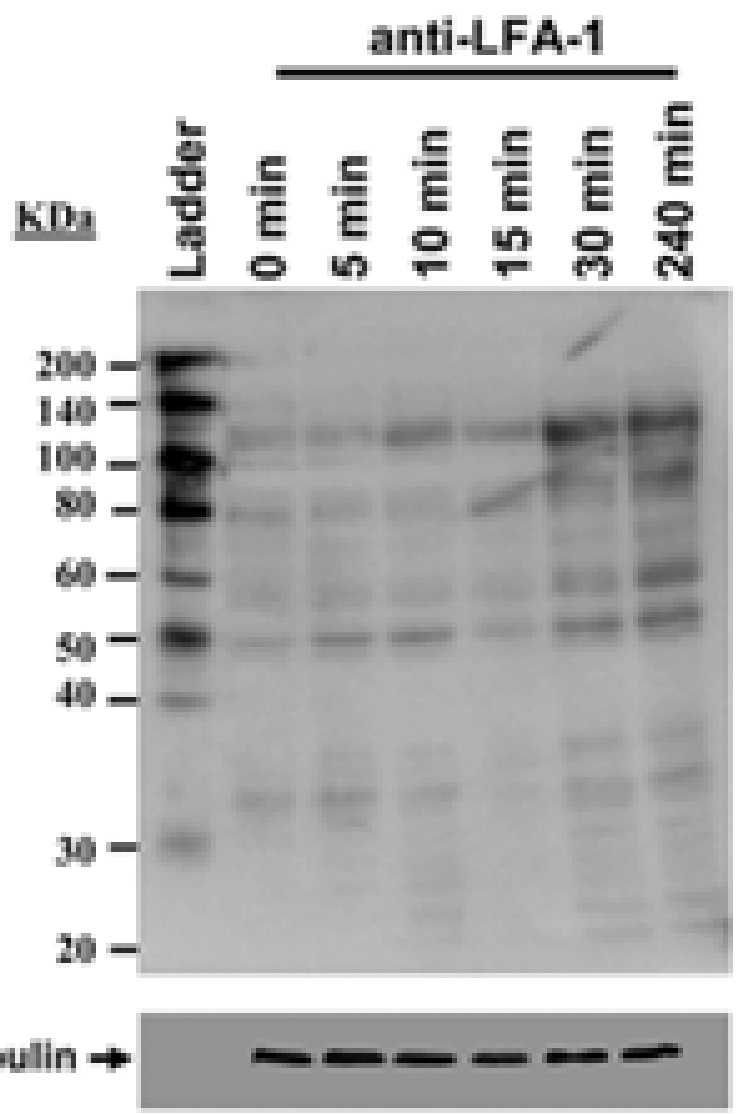




$$
\text { III }
$$


Figure 5

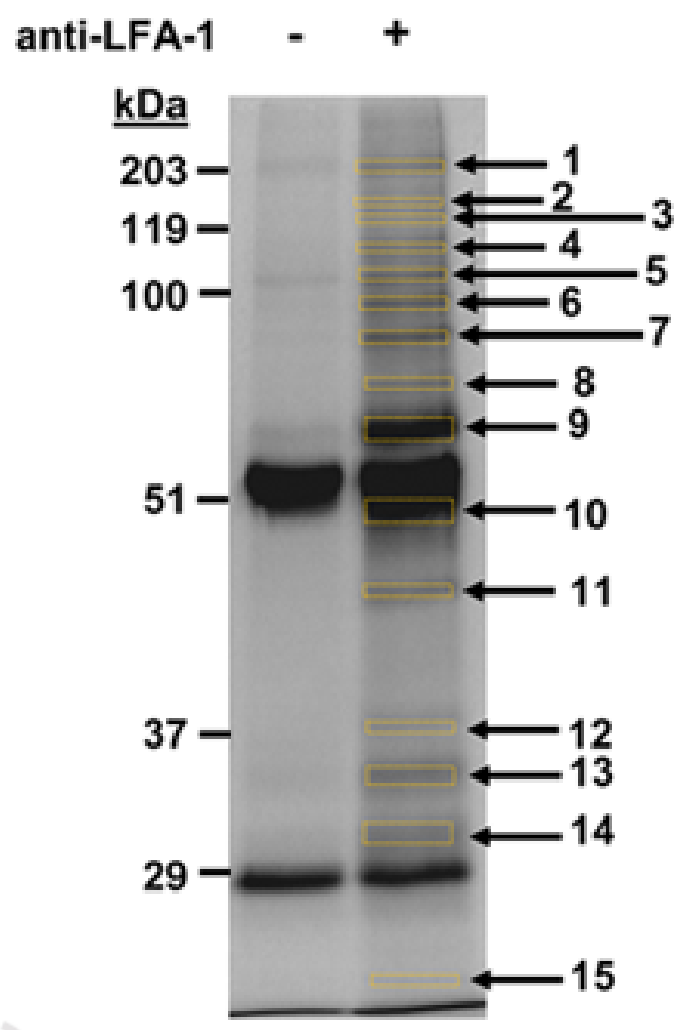


Figure 6

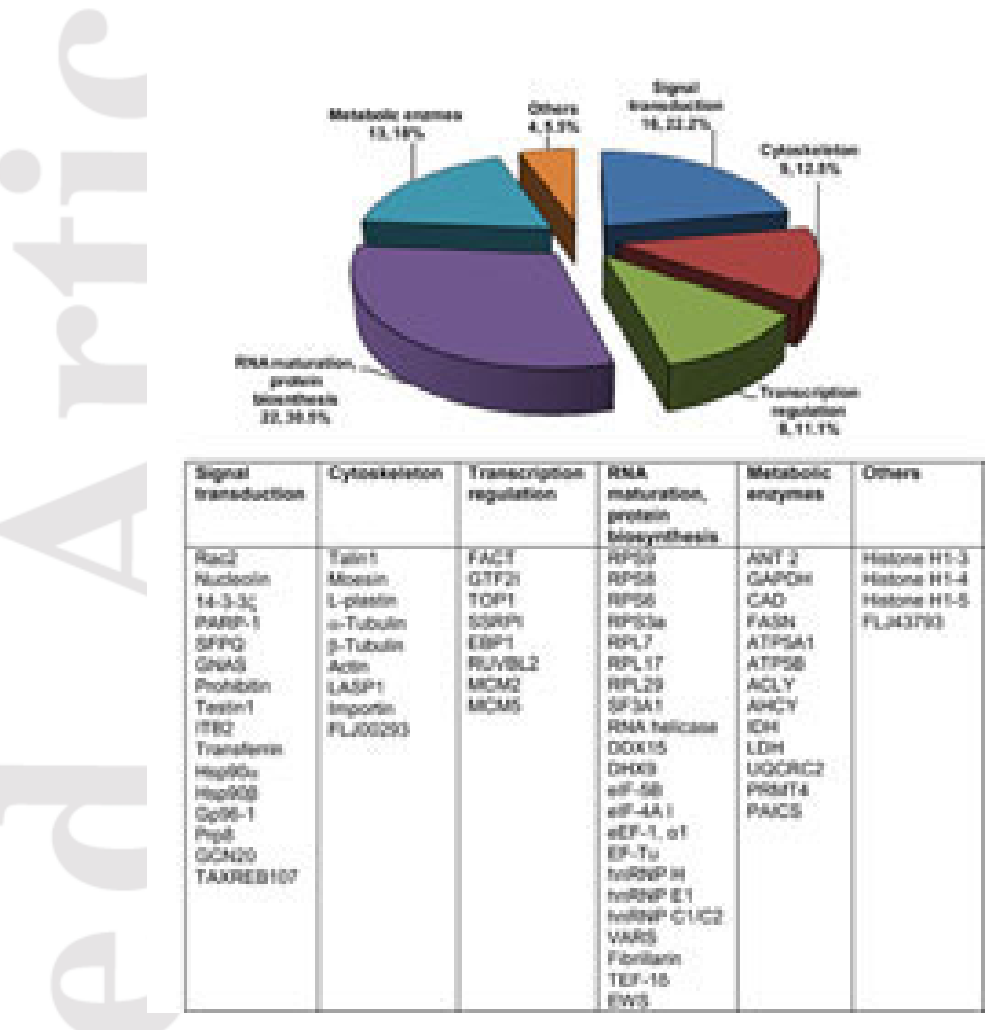


Figure 7

\section{A Hut78 cells}

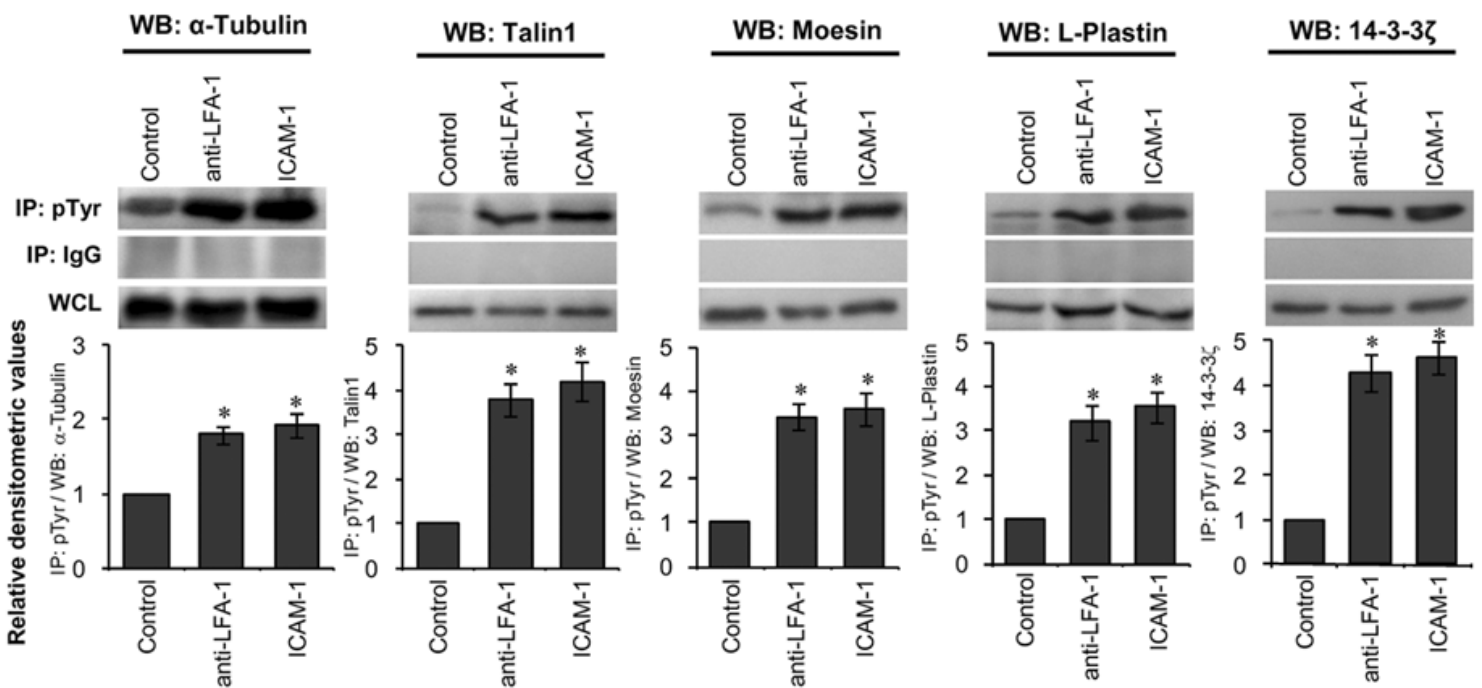

\section{B PBTLS}
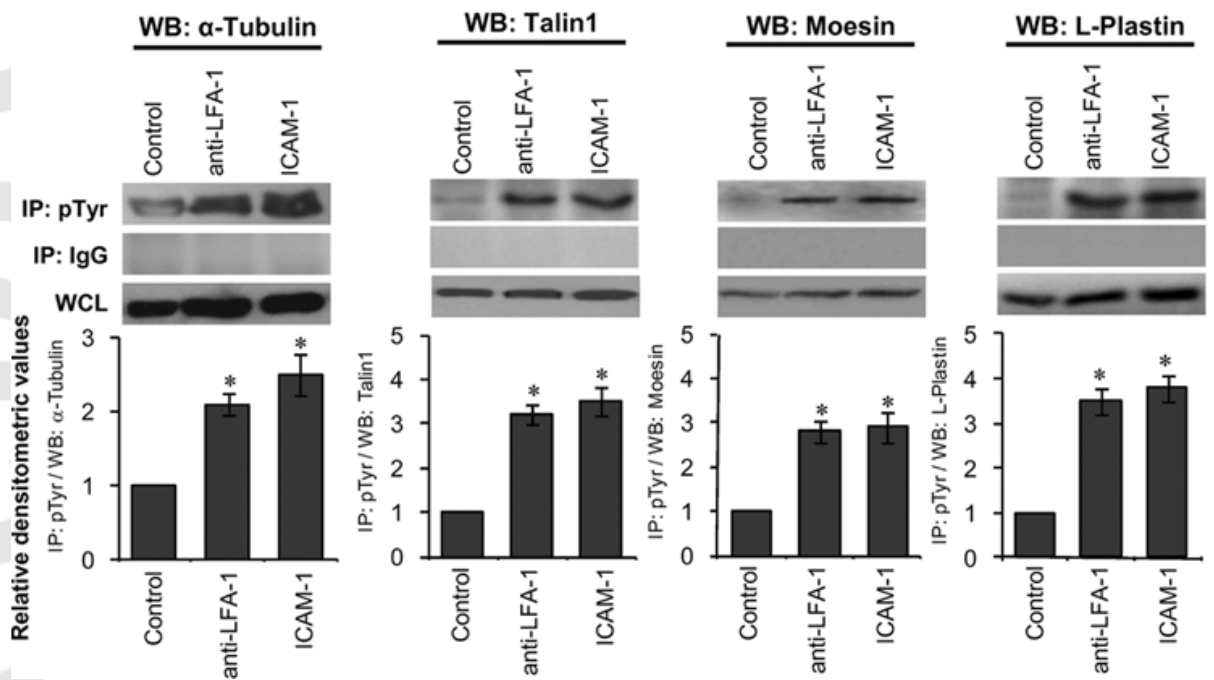

WB: $14-3-3 \zeta$
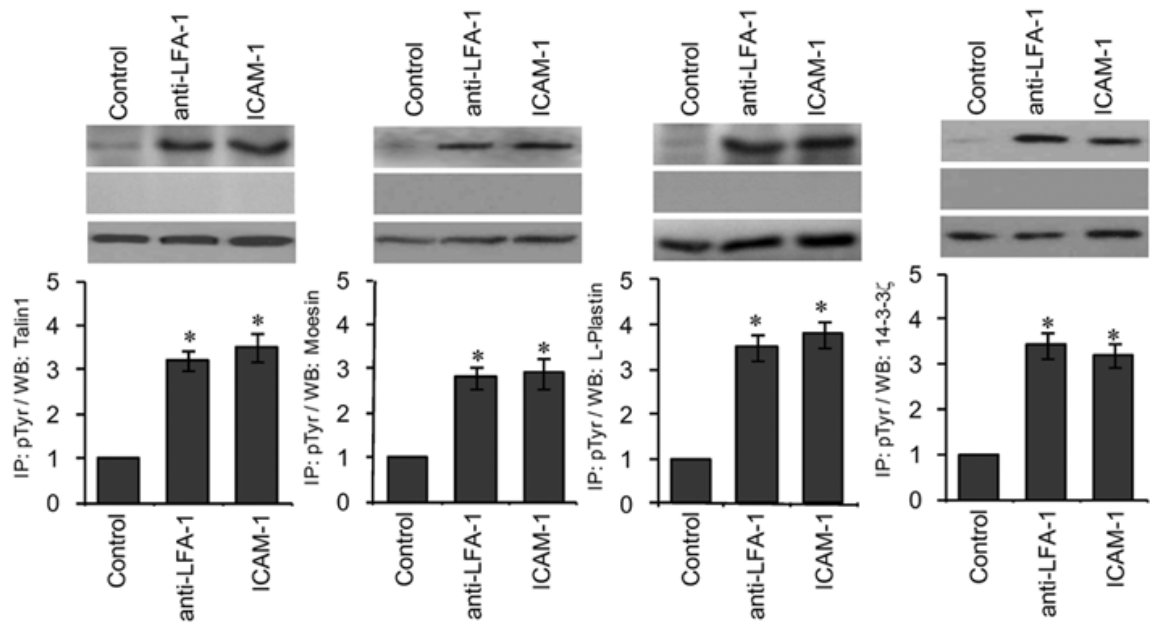


\section{Figure 8}

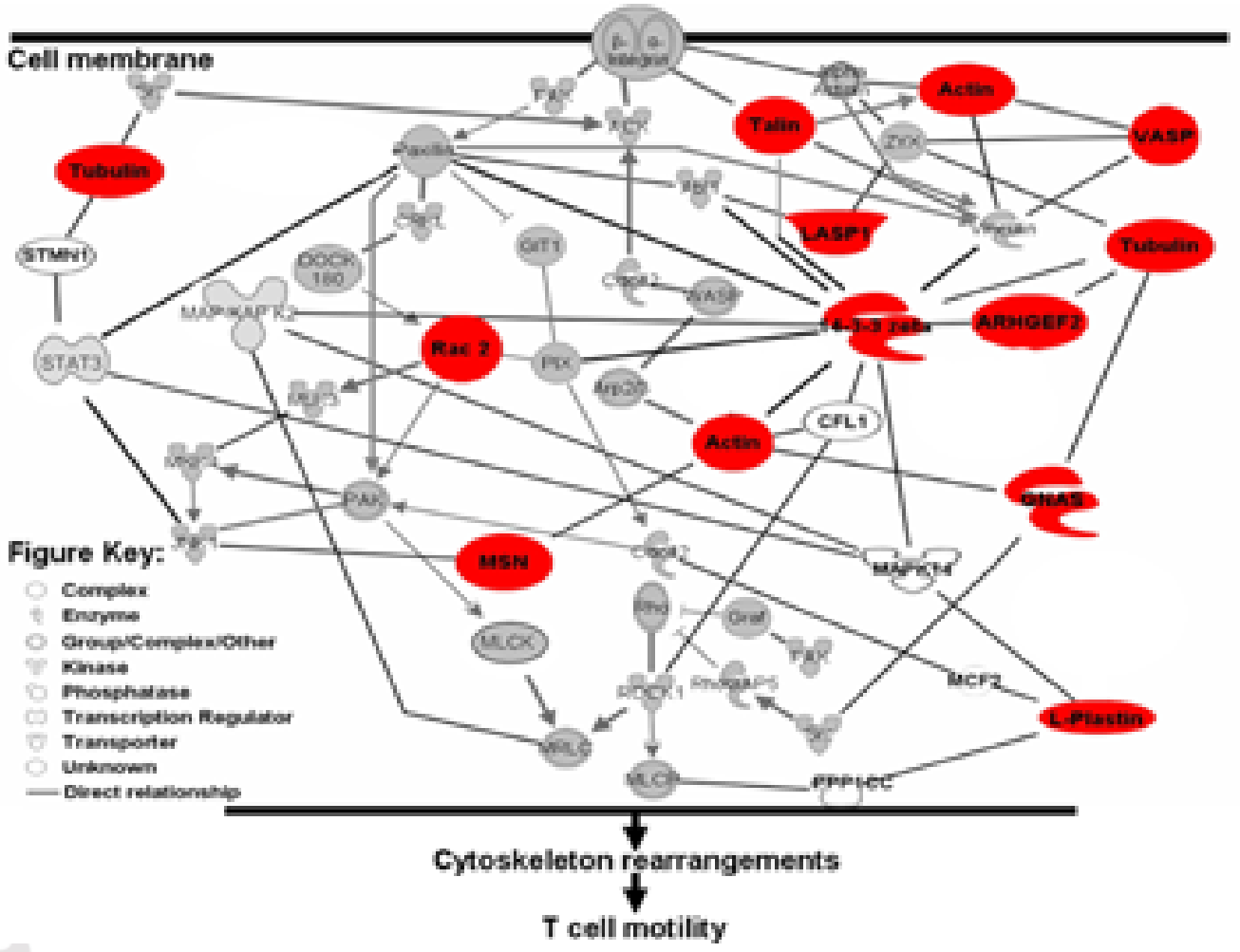

